\title{
Reconstruction post disaster responsive gender in West Sumatra
}

\author{
Mediana desfita ${ }^{1 *}$ and Djendrius ${ }^{2}$ \\ ${ }^{1}$ Civil Engineering Department, Andalas University, Padang 25163, Indonesia \\ ${ }^{2}$ Sociology Department, Andalas University, Padang 25163, Indonesia
}

\begin{abstract}
Indonesia is one of the very prone countries to disaster. The tsunami and earthquake disasters caused enormous damage to property and infrastructure as well as loss of life. An earthquake on September 30, 2009, measuring 7.9 on the Richter scale struck the west coast of Sumatra, causing loss of life and damage to infrastructure. There were around 1,115 people killed, 1,214 seriously injured and 1,688 people lightly injured. A comprehensive study of natural disaster management activities or systems should be used as learning materials to form a disaster management system. Disaster preparedness by minimizing vulnerability has been identified as a better approach to dealing with disasters than post-disaster response. Creating a culture of prevention is critical to dealing with everyday hazards and the consequences of disasters. The study is using data from a natural disaster in west Sumatra, and data from people who were involved in the process of reconstruction post disasters in west Sumatra. This study aims to obtain an accurate description of the reconstruction post-disaster and relation with responsive gender activities in West Sumatra, and identify how the gender effect on reconstruction post-disaster in the West Sumatra region.
\end{abstract}

\section{Introduction}

Post-disaster reconstruction activities without referring to gender aspects often make it difficult for women and children to continue their post-disaster life. Starting from the availability of shelters that are not safe and under the needs of especially women and children, the location of the shelters is far from the initial settlement and is in a position that is vulnerable to causing negative actions, because usually, its position is near the forest or mountains, far from the access. their daily activities, such as markets, schools, and health facilities. Likewise, the distribution of disaster aid has not paid attention to the special needs of this group of women and children [1].

In the context of disaster management in West Sumatra, gender considerations have received sufficient attention and are considered important to be integrated into the post-rehabilitation and disaster processes. However, in practice, there are still inconsistencies here and there. For example, gender-disaggregated data are not always available, gender analysis is not always applied in needs assessments for disaster response; assistance designs that do not always address the specific needs of each community group, aid distribution processes that do not involve/pay attention to the special conditions of women, children and vulnerable groups, temporary shelter designs that do not meet eligibility standards and the potential for increased violence against women, cases -cases have not been handled gender-based violence in refugee locations and temporary housing, [1].

Ideally, gender mainstreaming in post-disaster activities, both in the planning process, as well as in physical activities, must include gender factors in making directions and steps. This can be done if the gender factor is replicated and internalized into laws and regulations relating to post-disaster activities themselves so that the activities carried out are more integrated and support sustainable development.[1].

From all previous studies, it can be concluded that research on gender factors in post-disaster housing reconstruction activities needs to be investigated further, to reduce the level of vulnerability of women and children, as groups that are considered the most vulnerable in dealing with post-disaster conditions. This study aims to get an accurate picture of the gender position of post-disaster house reconstruction activities in West Sumatra. Knowing the effectiveness of genderbased post-disaster reconstruction activities on the matrilineal system in West Sumatra. Create a gender mainstreaming concept in post-disaster reconstruction activities in the West Sumatra region so that it can become an important part of legal guidelines and documents in post-disaster reconstruction activities in Indonesia, especially in West Sumatra. Generate a gender-friendly post-disaster shelter referral in this case to vulnerable groups of women and children.

* Corresponding author: mediana.desfita@yahoo.com 
Women and children are a gender group that, even under normal conditions, are very vulnerable. Especially in post-disaster conditions. So that post-disaster activities should no longer ignore gender in their implementation. Field experience shows that, 72 hours after a disaster occurs, women and children are vulnerable to violence in many forms. Meanwhile, the Huntara which was built without gender as one of the aspects reviewed resulted in a temporary shelter that did not create a sense of security for women and children. For this reason, it seems necessary to conduct research on gender mainstreaming in post-disaster reconstruction activities, which is carried out in the study area of West Sumatra, which is seen from its relationship with the order of Minangkabau cultural values, namely the Matrilineal System, which is very unique and is closely related to the position of women known as bundo kanduang. Which is the perspective of disaster is considered as a group with a high level of vulnerability, so that later there will be no post-disaster reconstruction, especially in the "Gender Blind" West Sumatra area.

In 2017, 335 natural disasters affected more than 95.6 million people, killed another 9,697 people, and cost a total of US\$335 billion. This problem is not the same for all places, as Asia is the continent most vulnerable to floods and storm events, with $44 \%$ of all disaster events, $58 \%$ of total deaths, and $70 \%$ of total affected people. Nonetheless, America reported the highest economic losses, representing $88 \%$ of the total cost of the 93 disasters. China, the US, and India are the countries most affected by this incident, marked by the occurrence in each country of 25,20 , and 15 events. Considering the land area in each country. [2]

Disasters in the last decade have resulted in significant losses in human life and livelihoods, economic and social destruction of infrastructure and environmental damage has increased the need for appropriate disaster reduction with risk management strategies. A disaster is described as part of a vulnerability. Since vulnerabilities are components of disaster dependency, they must be managed and minimized to reduce disasters. Disaster reduction policies and actions, which ensure the reduction of vulnerability, need to be established and implemented to achieve a sustainable and consistent disaster plan.[3].

One of the important elements in the effort to build a natural disaster management system is to evaluate and take important lessons from activities or natural disaster management systems that have been carried out so far. Strengths and successes, as well as weaknesses and failures in natural disaster management that have been carried out, will be important lessons for building a better national system for natural disaster management in the future. Thus, a comprehensive study of natural disaster management activities or systems should be used as learning materials to form a disaster management system.[4]

Disaster preparedness by minimizing vulnerability has been identified as a better approach to dealing with disasters than post-disaster response[5], creating a culture of prevention is essential to address everyday hazards and the consequences of disasters.[6]. Disaster risk reduction is defined as a conceptual framework, which considers the possibility of minimizing vulnerability and disaster risk across society, to avoid (prevention) or to limit (mitigation and preparedness) harm, in the broad context of sustainable development.[7]. Therefore, disaster risk reduction should be included as an important component of all national and local government development strategies, policies, programs, and investments[8]. In other words, disaster reduction includes taking action in advance, addressing risk reduction, involving environmental protection, social justice, and economic growth, the three cornerstones of sustainable development, to ensure that development efforts do not increase vulnerability to hazards.[9].

In disaster management, gender is also an interesting thing to study. We recognize that there are three categories in gender issues, namely gender responsiveness, gender bias, and gender neutrality. Gender responsiveness, namely the alignment of activities/activities or circumstances/conditions in supporting the implementation of gender roles such as women in the management of the post, hygiene kits include underwear and sanitary napkins, the number of toilets for women in the post is more, including gender aspects in disaster risk studies, lactation corners at refugee posts, gender vocal points in disaster management institutional structures, and the existence of guidelines for handling gender-based violence at disaster posts. Gender bias is the impartiality of activities/activities or conditions/conditions to support the implementation of gender roles, namely open toilets without covers, separate toilets for men and women, the assumption that the head of the family is always a man, reduced reproductive health services during emergencies, women are not involved in disaster management activities because they have been represented by their husbands/fathers/brothers and there are many other examples. Gender-neutral, namely activities/activities or conditions/conditions that do not contain the gender roles of men and women, for example, disaster-prone maps,[10].

Previous research has found that gender in postdisaster reconstruction is the result of unequal relations between women and men in society, and becomes women's vulnerability.[3]. Therefore, socially constructed roles often make women more vulnerable to harm. Gender shapes the social world in which natural hazards occur,[11]. Therefore, "gender-blind" reconstruction policies and programs can only lead to increasing women's vulnerability, widening gender gaps, and creating unsustainable development in affected communities.[12]. Studies have found that failure to address gender issues in post-disaster reconstruction (PDR) policies and programs hampers opportunities for reconstruction to achieve community resilience and sustainable development.[13]. Thus, gender mainstreaming is very important to achieve sustainable development through reconstruction.

Although women are at greater risk than men in disasters, it is women who enable the community to be able to cope with disasters because their social role is very important in managing disaster management strategies,[11] and [14]. However, the ability of women to reduce hazards and prevent disasters as well as cope with 
and recover from the impacts of disasters has not been sufficiently calculated or developed. In the current practice of disaster management women are seen as helpless victims and their capacities, knowledge, and skills at every stage of the disaster cycle are not recognized.[15]. Gender differences in disaster mitigation have been discussed mainly in the context of vulnerability or community involvement. The absence of women in decision-making positions in emergencies results in ineffective recovery planning. Therefore, a gender perspective should be integrated into all disaster risk reduction policies and measures to reduce women's vulnerability in disasters. However, gender equality in disaster reduction requires empowering women to have increased roles in leadership, management, and decisionmaking positions because women are not only disaster victims but they can act as change agents in disaster reduction planning.[16].

Therefore, gender mainstreaming needs to be incorporated into policies and programs related to disaster reduction, especially because "gender shapes capacity and vulnerability to disasters.[17] as previously discussed. gender mainstreaming can promote gender equality and women's empowerment, especially if there are glaring examples of persistent discrimination against women and inequality between women and men. Gender mainstreaming can be used as an effective tool to reduce women's vulnerability, which arises due to various factors including lack of access to resources and more women entering the disaster reduction policy-making process. However, increasing gender mainstreaming is a lengthy process that requires input from many parties over a long period, including advocacy, advice and support, competency development, development of methods and tools, and vigilance in following up and evaluating progress.

The province of West Sumatra, known as the Minang realm, currently has a population of 4,528 million people. Some residents of this area, although listed as Minangkabau residents, are domiciled overseas. The Minangkabau people are the largest matrilineal ethnic group in the world and the only example for Indonesia. Its social and political organization approaches a purely matrilineal type from an anthropological point of view. However, they have also long been known as steadfast adherents of Islam, as is their market-oriented and outward-looking mental attitude. On this basis, the Minang people in Indonesia are often considered the rightful owners of the wandering tradition, [18].

The culture of the Minangkabau community is embodied in the philosophy of Tigo Tungku Sajarangan or Tigo Tali Sapilin, where the role of the three main forces is represented by the ulama, niniak mamak, bundo kanduang, and cadiak clever, which is a formal force in a matrilineal society. Socio-culturally Minangkabau women, or also known as bundo kanduang, have a unique position in Minangkabau customary law, especially in the lineage system taken from the maternal line (matrilineal). Economic resources and their use are also for women. Meanwhile, in the context of political dynamics in indigenous communities, especially in deliberations for families, the voice of bundo kanduang determines the results be achieved [18].

Women in Minangkabau have a very important position in tribes, tribes, and villages. In this case, women function as heirs of high inheritance from mamak to their nephews in the clan or tribe. Minangkabau custom places women in a very noble position. The role of women is seen in the principle of the matrilineal kinship system[18].

\section{Methods}

The research methodology framework of this study adopts the 'research onions' model proposed by Saunders et al. (2019) [20]. The assumptions of the research philosophy are taken from several case studies that are used as research strategies. This study uses a mixture of qualitative and quantitative methods. In achieving its aims and objectives, a quantitative approach is used as the main method. The first data collection method (semi-structured interview) aims to identify post-disaster Reconstruction Activities with a gender-based approach. At the same time, a questionnaire survey to assess the probability and level of gender-based post-disaster reconstruction activities in the Matrilineal System in West Sumatra was identified. Content analysis was performed for qualitative analysis, while descriptive and inferential statistics were used for quantitative analysis.

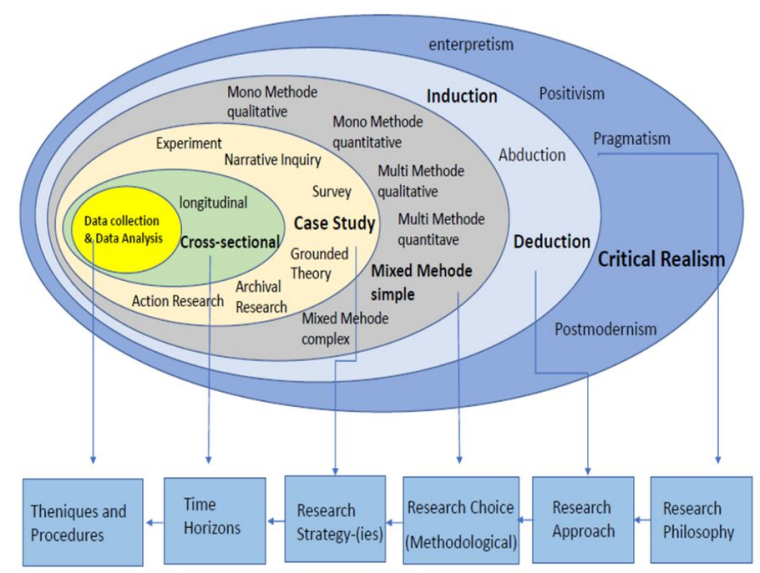

Fig 1: The research process "The Research Onion", Saunders et al. (2019)

The flow chart of the research phase can be seen in Fig 2. 


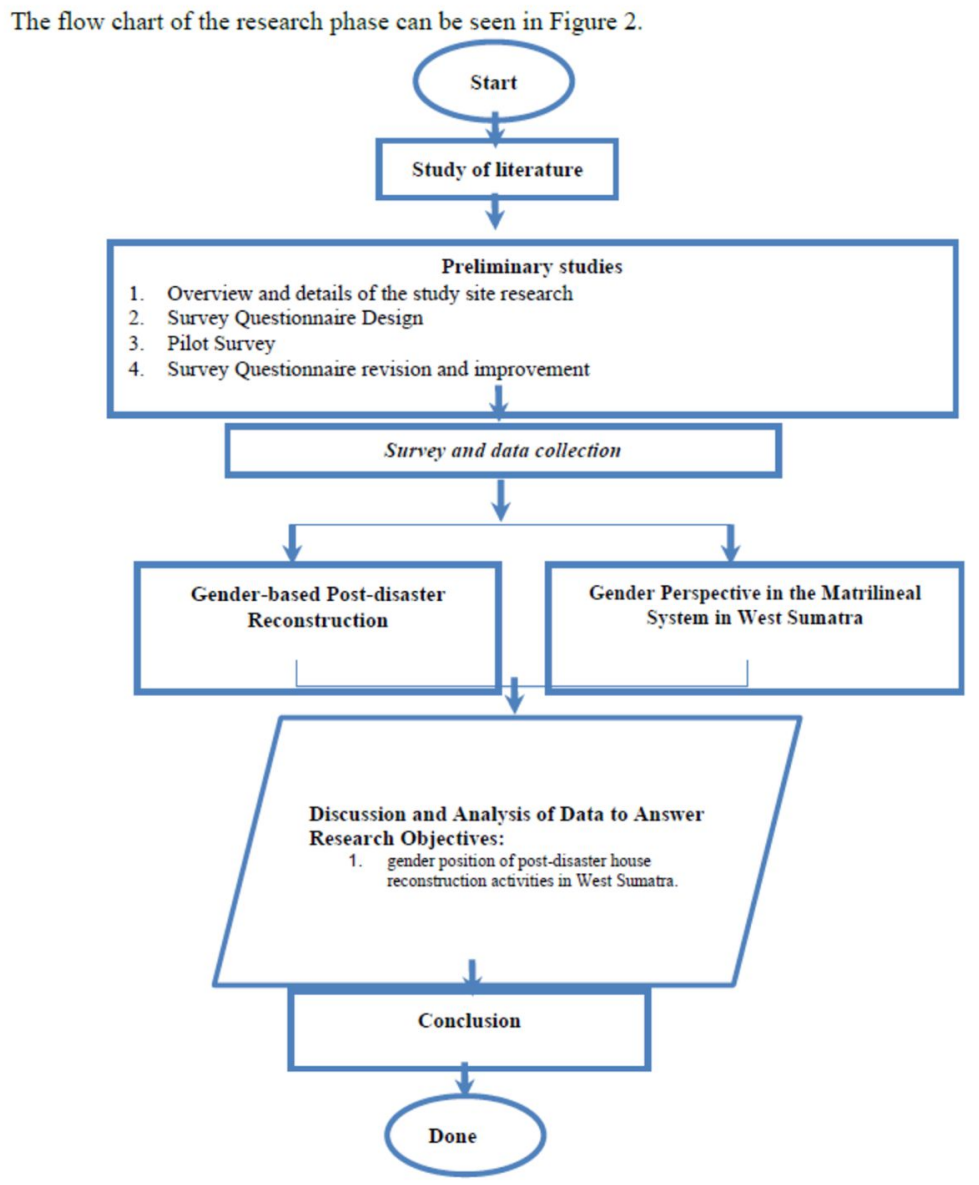

Fig 2: Flowchart of Research Stages

\section{Results and Discussion}

This research begins with a literature review on disasters, trends in natural disasters in the world, trends in natural disasters in Indonesia, and trends in natural disasters in the study area, namely West Sumatra. Furthermore, a literature review was conducted regarding post-disaster reconstruction activities that have occurred so far, both post-disaster reconstruction activities in the world, postdisaster reconstruction activities in Indonesia, and postdisaster reconstruction activities in the study area, namely in West Sumatra. In general, and the gender perspective concerning post-disaster reconstruction activities so far, the author here also looks for correlations between gender mainstreaming and post-disaster reconstruction activities, both in the planning stage and in the implementation stage in the field. Furthermore, the author also examines the study area, namely West Sumatra, both in terms of geographical, socio-cultural, and socio-economic conditions. Then more deeply this literature review will review the matrilineal system as a cultural order in the study area, both in terms of cultural aspects and its relation to post-disaster reconstruction activities.

The study Desk which initiated this research became the basis for the implementation of the preliminary study phase. Where at this stage, the author has introduced an overview and detailed situation of the study area related to the research to be carried out. Then the author began to design a questionnaire, as a tool in this research activity which aims to obtain the data and facts needed, to achieve the objectives of the implementation of this research. The next activity is to conduct a pilot survey to know how far this questionnaire design can answer the ability to accommodate data needs in later research. After that, revisions and improvements are made based on the results of its effectiveness in the pilot survey. At this stage, the questionnaire is considered feasible to be distributed to respondents.

The next stage is an important part of this research, namely the distribution of questionnaires that have been refined in the previous stage, which aims to collect the data needed in this study. The respondents who will be addressed in this study are people who are closely related to post-disaster reconstruction activities in West Sumatra, Indigenous Stakeholders, and the Minang Kabau Community, especially Bundo Kanduang who is the center of this research. The questionnaire as a research tool is divided into two parts, namely a questionnaire on gender-based post-disaster reconstruction, and a questionnaire on gender perspectives in the value system of the matrilineal system in the study area, namely West Sumatra. at a later stage, The relationship between these two things can be found, which is intended to answer the objectives of this study. This stage is considered complete when all data has been collected. 
The next stage is the discussion and data analysis, which is carried out to get answers to the objectives of this study, namely: Identify gender position of post-disaster house reconstruction activities in West Sumatra; in this case, to vulnerable groups of women and children.

\section{Conclusion}

In the context of disaster management in West Sumatra, gender considerations have received sufficient attention and are considered important to be integrated into the post-rehabilitation and disaster processes. However, in practice, there are still inconsistencies here and there. For example, gender-disaggregated data are not always available, gender analysis is not always applied in disaster response needs assessments; assistance designs that do not always address the specific needs of each community group, aid distribution processes that do not involve/pay attention to the special conditions of women, children and vulnerable groups, temporary shelter designs that do not meet eligibility standards and the potential for increased violence against women, cases -cases have not been handled gender-based violence in refugee locations and temporary housing, etc. For this reason, it is necessary to conduct more significant research related to the correct integration of gender in post-disaster reconstruction activities in West Sumatra, so that the problems that occur can be overcome.

\section{References}

1. K.-S.Gender Working Paper, 1-14 (2011)

2. L. (2544), Report of the Learning Circle Association for Women, Central Sulawesi, (2020).

3. M.M. Ariyabandu and Wickramasinghe, Gender Dimensions in Disaster Management - A Guide for South Asia, Colombo: ITDG South Asia. Natural Hazards and Earth System Sciences, 18 (6), 17851810 (2003)

4. BNPB, Indonesian disaster risk (2016)

5. S. Childs, and M.L. Krook, Gender and politics: The state of the art. Politics, 26 (1), 18-28 (2006)

6. J. Drolet, L. Dominelli, M. Alston, R. Ersing, G. Mathbor, and $\mathrm{H}$. Wu, Women rebuilding lives postdisaster: Innovative community practices for building resilience and promoting sustainable development. Gender and Development, 23 (3), 433-448 (2015)

7. E. Enarson, , "Gender and Natural Disasters", IPCRR Working Paper no.1, International Labor Organization. In Natural Disaster Risk Management: Geosciences and Social Responsibility, (2016)

8. Enarson, Elaine, Review of Women confronting natural disaster, From vulnerability to resilience. American Journal of Sociology, (2012)

9. K. Ginige, University of Huddersfield Repository Gender mainstreaming in disaster reduction: why and how? (2008)
10. isdr2002ZentelGlade2013International_Strategies_f or_Disaster_Reduction.pdf. (nd).

11. H. Khatun, Livelihood strategies in disaster risk reduction in Bangladesh, In Sahni, P., and Ariyabandu, MM(eds.), Disaster Risk Reduction in South Asia, New Delhi: Prentice-Hall of India. (2018)

12. ME. McGuinness, Secretary or General? The UN Secretary-General in World Politics. Edited by Simon Chesterman. Cambridge, New York: Cambridge University Press, 2007. Pp. xiv, 280. Index. \$85, £45, cloth; \$31.99, £16.99, paper. American Journal of International Law, 102 (4), 930 936 (2008)

13. Saunders; K.LEwis, Philip; Thornhill, A., Research Methods for Business Students (Eighth edi), New York: Pearson, [2019]: Print edition typeset in 9.5/12 ITC Slimbach Std by Pearson CSC (2019)

14. Secretary-General, Implementation of the International Strategy for Disaster Reduction: Report of the Secretary-General to the UN General Assembly. 14, 470-486 (2015)

15. A.B. Shamsul, Change and Continuity in Minangkabau: Local, Regional and Historical Perspective on West Sumatra. Edited by Lynn L. Thomas and Franz Von Benda-Beckmann. Monographs in International Studies Southeast Asia Series No. 71. Athens, Ohio: Ohio University Center. Journal of Southeast Asian Studies, 20 (1), 124-126 (1989)

16. í, F. . G.. Terminology of Disaster Risk Reduction (2009)

17. E. Sunarti, Evaluation of disaster management in Indonesia (Lesson learned 2006-2007). Retrieved from 202.124.205.241/handle/123456789/53265 (2007)

18. Tesco. Annual Report. Retrieved from https://www.tescoplc.com/media/392373/68336_tes co_ar_digital_interactive_250417.pdf (2017).

19. United Nations. UNISDR / 2004 / 0826 October 2004 NATURAL DISASTERS: RICH COUNTRIES ALSO PAY THEIR TOLL. 33(October), 2759 (2004)

20. A. Yonder, S. Akçar, and P. Gopalan, Women's participation in disaster relief and recovery. In Women, Gender and Disaster: Global Issues and Initiatives (2009)

21. T. Yumarni, D. Amaratunga,Gender mainstreaming as a strategy to achieve sustainable post-disaster reconstruction. Built Environment Project and Asset Management, (2018).

22. T. Yumarni, D. Amaratunga, R. Haigh, Assessing Gender Vulnerability within Post-earthquake Reconstruction: Case Study from Indonesia. Procedia Economics and Finance, 18(September), 763-771 (2014). 